\title{
El papel de los periodistas desde la perspectiva de un contexto trascendente
}

\section{The paper of the journalists from the point of view of a "transcendental" context}

\author{
Luis Núñez Ladevéze. Universidad CEU San Pablo
}

Recibido: 24-VII-2013 - Aceptado: 02-II-2014

Resumen:

El punto de vista expuesto trata de mostrar la compatibilidad interna y el modo en que se resuelven en uno solo los compromisos doctrinal y profesional afrontados por un periodista cristiano. Se analizan casos concretos estudiados principalmente en discusiones de seminarios de doctorado. El esquema de la argumentación procede de una teoría de la interpretación aplicada en particular a los textos periodísticos. La fórmula propuesta se basa en la aceptación del criterio de que toda afirmación de una verdad lo es con referencia a un contexto. Y, si se acepta el de la "trascendencia”, de lo que se trata es de ser consecuente con ese contexto, sin que esa consecuencia afecte a las reglas deontológicas y profesionales de elaboración y construcción del texto periodístico en su propio contexto. El trabajo se propone explicar qué condiciones se cumplen para asegurar que la verdad del contexto trascendente sea compatible con la del texto informativo, y viceversa.

Palabras clave:

Verdad, contexto, noticia, interpretación, multiculturalismo, magisterio, ciencia.

Abstract:

The point of view hereby shown tries to prove the internal compatibility and the way to solve both the doctrinal and professional commitments faced by a Christian journalist. Actual cases that have been discussed in pre-doctoral seminars are analyzed. The system used in the argument it comes from a general theory of interpretation specifically applied to journalistic texts. The formula proposed is based on the acceptance of the idea that any statement of a truth is referred to a context. And, if the context of "transcendental" is accepted, one must be coherent with this context. However, this consequence should not affect the rules of creation and construction of the journalistic text. This paper is aimed at explaining the conditions to be fulfilled to guarantee that the truth in the interpretative context should be compatible with the truth in the informative text and vice versa.

Key words:

Truth, context, news, interpretation, multiculturalism, teaching, science. 


\section{Introducción}

Este trabajo comprende dos partes. En la primera, se examina cómo compromete a la función informativa la solicitud de contribuir a una "nueva evangelización”. En la habitual distinción entre periodismo de opinión y periodismo de información se puede suscribir que ese compromiso corresponde a la "opinión" libre de los periodistas que pueden expresar sus puntos de vista en los géneros de opinión. Pero el problema consiste en saber si esa recomendación afecta y cómo a los periodistas cuando realizan información suscribiendo implícita o expresamente una recomendación doctrinal. ¿Puede la "información periodística" supeditarse o ponerse al servicio de una encomienda basada en una creencia? Esta es la pregunta que se busca responder.

Para tratar esta cuestión se recurre a métodos hermenéuticos fundados en la tradición fenomenológica, el interaccionismo, la teoría del texto y la analítica de los actos de habla. Como servicio a la economía de las referencias el autor se limita a fuentes explícitas y a alusiones a su propia obra donde remite a conceptos, influencias y bibliografía que quedan tácitamente sintetizados en el texto.

En esta fase, tras la tarea exegética de dilucidar el sentido histórico, se ocupa de indagar las condiciones de compatibilidad, en el caso de que las haya, para que una deontología profesional, cuyo fundamento es atender a la verdad informativa, pueda a su vez servir de cauce a una exhortación doctrinal como la de contribuir a la "nueva evangelización". Tras precisar algunos recursos metodológicos requeridos para el uso de conceptos en el marco de una teoría analítica de la significación, la conclusión suscribe que la verdad de la información se sitúa en un contexto inmanente en el que hay que cumplir las condiciones deontológicas propias de ese marco, las cuales no tendrían por qué contradecir las recomendaciones de una perspectiva contextual trascendente si se cumpliera el requisito de que no haya incongruencia con las exigencias inherentes a la inmanencia. Se argumenta la tesis de cómo se dan las condiciones de compatibilidad y trata de mostrarse cuáles son.

La segunda fase remite a una exposición de conclusiones de casos prácticos que se propusieron en sesiones de seminario de doctorado con investigadores en etapa de formación a los que se planteó justamente el problema de si era posible compaginar ambos puntos de vista sin que uno contaminara al otro. Se discutieron los casos y se examinaron las propuestas a fin de comprobar si el enfoque inmanente podría satisfacer las condiciones de una recomendación trascendente o si esta pretensión podría ser un condicionante que solo puede satisfacerse tergiversando el valor de verdad informativa socialmente regulado.

Admitido que ambas perspectivas no se interfieren si se infiere que el valor de verdad en un contexto depende de las reglas del marco donde pretende hallar validez, la parte final del artículo se centra en encontrar un sentido concreto a la expresión "nueva" del sintagma "nueva evangelización": dónde situar una "novedad" aplicada a una tarea tan vieja como la de la propuesta evangelizadora arraigada en el Cristianismo. 


\section{Límites del análisis hermenéutico}

Tratar del tema de El papel de los informadores desde la perspectiva de un contexto trascendente como el de la nueva evangelización tiene complicaciones de diverso tipo ${ }^{1}$. La principal se refiere a la dificultad de separar los estatutos correspondientes a un tratamiento científicamente objetivista de los de un enfoque doctrinal. La distinción entre un metalenguaje enunciativo y un lenguaje objeto ha sido el recurso analítico habitualmente utilizado para separar los análisis científicos y los tratamientos doctrinales, de modo que lo doctrinal sería el objeto de un estudio científico. Pero esa disociación no es fácilmente aplicable en los casos en que se enjuician proposiciones de un tema desde un metalenguaje que no puede razonablemente pretender dejar de ser objeto, a su vez, de las proposiciones judicativas si el lenguaje objeto enjuiciado se erigiera en metalenguaje ${ }^{2}$.

Esta dificultad llega a ser aporética en la sociología científica. Toda sociología y, en particular, la de la ciencia, es un instrumento de análisis cuya pretensión de validez es llegar a conclusiones objetivas sobre el objeto de estudio, en este caso, la ciencia, por lo que sus reglas de validez se miden por las mismas reglas que validan el campo de estudio. Por decirlo así, es juez y parte. En cuanto a la hermeneusis fenomenológica, forma parte del proceso sobre el que versa su exploración, de aquí que la tarea exegética sea a la vez un fenómeno para esa misma tarea. Como suele decirse, la pescadilla se muerde la cola. Y, en general, la pretensión científica de someter a examen una corriente doctrinal externa al dictamen científico puede, a su vez, ser objeto de comentario crítico de la doctrina que trata de dictaminar. La pretensión científica de situar a la ciencia au dessus de la melée ha sido ampliamente censurada en la obra de Feyerabend cuyos razonamientos en buena parte suscribimos (1981 y 1982).

Estas indicaciones previas están directamente relacionadas con el asunto sobre el que versa este trabajo cuyo objeto analítico es el enjuiciamiento de un requerimiento doctrinal desde un enfoque objetivista, que se vale de una metodología hermenéutica y analítica que pretende desprenderse de las condiciones existenciales del sujeto que investiga. Cualquiera que sea la cosa que signifique "objetivo", lo que se supone como regla práctica, es que la coherencia interna del orden propositivo construido tenga validez por sí mismo y sea aceptable independientemente de las preconcepciones o presunciones adoptadas desde otro enfoque. Por cierto, se trata de una aspiración no invulnerable a las aporías antes señaladas. Esa convicción, fundamentada en la obra de Gadamer (1977), orienta el trámite de este comentario para considerar que la pretensión de validez de un "contexto trascendente" ha de admitirse como hipótesis de investigación, al menos en las mismas condiciones que la presuposición de objetividad enunciada desde la posición inmanente.

\footnotetext{
El texto se ha elaborado desde una perspectiva teórica y metodológica centrada en que la noción de "contexto trascendente" ha de admitirse como hipótesis de investigación, no menos que la presuposición de objetividad. El término "contexto trascendente" no pretende ser un eufemismo para evitar usar "religión”. Sobre las dificultades del uso de la palabra "religión” puede verse Werblowsky, 1981.

2 Entiendo por "contexto" un ámbito de interpretación de una unidad significativa. En este caso, el contexto queda excluido del alcance que pueda darse a un "marco de interpretación inmanente". Remito a asunciones del autor, expuestas en la bibliografía citada, sobre teoría analítica relativas a las condiciones de interpretación.
} 


\section{Hermenéutica del proceso}

La pregunta sobre la verdad de la información tiene un sentido específico cuando se trata de un periodista que entiende y acepta la apelación a cooperar con una "nueva evangelización". La perspectiva de un contexto trascendente se concreta en estas líneas con referencia a esa propuesta de "la nueva evangelización”. Son dos los asuntos implicados. El primero, se refiere a las condiciones de compatibilidad de un tratamiento profesional de la información que, a la vez, quede al servicio de la asunción de un contexto o "encuadre" orientado a "la nueva evangelización”. El segundo, y solo como colofón, qué cabe entender por "nueva" en el programa de la evangelización desde esa perspectiva, asunto que se abordará como desenlace en la breve parte final del trabajo. El problema de fondo radica en que una respuesta normativa implica algún tipo de compromiso con alguna noción normativa de verdad. Y lo que se plantea es si el compromiso doctrinal antecede o no al profesional, si lo altera, o si ambos compromisos son o no compatibles con un mismo valor común de verdad informativa.

Nos proponemos mostrar que se dan las condiciones para que un mismo valor de verdad informativa sea respetado en ambas perspectivas, y que, en consecuencia, no haya riesgo objetivo, (otra cosa es el subjetivo) de que se interfieran o contagien. A esta afirmación no se llega por inadvertencia de lo que implícitamente entraña el anuncio de una "nueva" etapa evangelizadora: la tácita admisión de que la tarea precedente se ha desgastado, del envejecimiento de un proceso que, por anticuado, o en parte frustrado, es preciso renovar. No sería necesaria esa exhortación si las velas fueran viento en popa. No puede ignorarse, pues, este aspecto de la cuestión como tampoco lo ignoran a veces las invocaciones a esa tarea. Como las muestras son patentes en las numerosas fuentes doctrinales accesibles, no es momento de detenerse a exponer lo que está al alcance fácil del estudioso y expreso, como veremos, en los textos aquí utilizados como referencia básica. La exposición se aplica a la labor hermenéutica de comprender estos documentos en su transcurso histórico, aunque en esos mismos documentos se suela abordar esa labor desde una dimensión eclesiológica o teológica, la cual, por asegurar la salud metodológica de este estudio, deliberadamente se rehúye en el texto.

Los documentos se refieren en términos a veces expresivos a los estragos que el proceso de secularización iniciado tras las guerras de religión europeas y, en parte, como consecuencia de ellas, experimentó la tradición cristiana del medievo. No es momento de aludir a los forcejeos entre reforma y contrarreforma, a la capacidad de resistencia del viejo para evitar su mutación en nuevo régimen, (por utilizar las descripciones acrisoladas desde Tocqueville), al repliegue intelectual frente a la progresiva emancipación de la filosofía, que deja de ser ancilla, a la autonomía de las hipótesis teóricas de las ciencias empíricas y el impacto social de sus progresivas aplicaciones, especialmente las relativas a la tecnología de la comunicación, como la imprenta, la rotativa, la radio y la televisión, tan eficaces para la construcción de un espacio público de opinión no controlado por la doctrina... Conceptos distintos tan interdependientes, por haberse producido simultáneamente en la convergencia histórica, que merecerían deslindarse conceptualmente unos de otros, desmenu- 
zarse o tipificarse, como el concepto de modernidad frente a los de secularización, democracia, liberalismo, laicización o, en fin, postmodernidad ${ }^{3}$.

Que esto sea así, no se pone en duda en los documentos, pero no solo no desvirtúa el fondo de la cuestión que abordamos, sino que también permite sorprenderse, sin abandonar la mirada hermenéutica, de que no haya sucumbido durante este forzoso repliegue condicionado por tan poderosos impulsos. Como observaba ya hace tiempo Werblowsky, al examinar el enmarañado tema de las relaciones entre tradición religiosa y modernidad occidental, "la modernidad convierte el pasado en problemático... y parafraseando a Mahdi "se ha convertido ella misma en una tradición"..."la tradición cambia modernizándose y la modernidad cambia 'tradicionalizándose'” (31-36 y 151 y ss.) Y este es el núcleo de la cuestión que se plantea a la labor exegética: en qué sentido esta propuesta de renovación (no de "innovación") es congruente con los requisitos impuestos por un proceso de modernización que, a la vista de la propia nomenclatura al uso, ha acabado consumando su ciclo transmutándose en postmodernidad, cualquiera que sea el significado que haya de darse a esa expresión. Que, a la postre, haya sido la modernidad la que haya acabado transformándose o sucumbiendo, y no la envejecida tradición que combatían algunas de sus más radicales y poderosas motivaciones, no deja de ser un motivo de sorpresa para una mirada analítica, un asunto digno de examen y de estudio ${ }^{4}$.

En fin, observada desde esta perspectiva, la historia de la evangelización pasa por esas y otras distintas fases. La más llamativa, acaso un momento culminante de despliegue por un nuevo mundo, coincide con el estallido del germen que da lugar a una estampida que lleva a muchos durante el proceso ilustrado a vaticinar su descomposición y, a otros, a procurarla activamente ${ }^{5}$. Son evidentes los signos de repliegue, la resistencia al cambio, a la adaptación a una nueva situación frente a las que, las fuerzas concentradas tras la unidad espiritual de referencia que fue el Medievo, trataron de amurallarse para evitar desmoronarse. Que aparezca hoy transformada, pero en buena parte indemne, de esos flujos y reflujos, conduce al estudioso a ponderar de dónde emana esa capacidad de desprendimiento para la conservación, de mutación de lo accesorio para el mantenimiento de lo sustancial ${ }^{6}$. Si solo fuera empeño de resistir a cualquier precio, sería inexplicable que, en terrenos que ya no son abonados por un fervor favorable ${ }^{7}$, hubiera restablecido su energía para encauzar un lide-

3 La literatura sobre estos conceptos es ingente. Muchas veces se tratan de manera sinónima. Para un planteamiento novedoso de aclaración de estos términos véase Tschannen, 1992. Para el concepto de “laicización”, véase Bauberot 2007.

4 Para una visión de las actitudes ilustradas sobre la religión cfr. Fraijó 1994.

5 Como botón de muestra, la percepción generalizadora de un historiador de la magnitud de Burckhardt: "en la literatura del siglo XVIII estalla abiertamente la aversión de los espíritus contra la Iglesia católica como una pura negación” (1961: 205). La interpretación más solvente suele señalar a La esencia del cristianismo de Feuerbach como consumadora filosófica de esta ruptura.

6 ¿Dónde situar el límite de lo sustancial y lo ritual? "A cualquiera que no le guste el catolicismo de hoy debería abandonarlo y hacerse protestante, o ateo, en lugar de degradarlo mediante cambios insustanciales como la misa en lengua vernácula” (Feyerabend, 1981:303).

7 Volviendo a Burckhardt como fuente de autoridad: "La cultura en forma de filosofía e investigación demuestra al cristianismo sus orígenes humanos y su condicionalidad, adopta ante los textos sagrados la misma actitud que ante los demás... ante una concepción racional de la naturaleza y la historia, sería absurdo admitir la posibilidad de un territorio exento" (Ibid). 
razgo espiritual en la copiosa confluencia de culturas que entran en la liza de la aldea global. Tampoco se trata solo de adaptación, pues, aunque haya renovación de vestiduras y de formas, lo que importa es que no se atisba claudicación sobre la universalidad de los conceptos que se proclaman perennes, que transmiten en el decurso una incólume identidad originaria.

El aspecto práctico de la cuestión, que se examina en la segunda parte de este artículo, tiene por fin pulsar el origen y la firmeza intrínseca de ese fondo permanente de resistencia probándolo en discusiones abiertas en sesiones de seminarios. En esta parte se citan prácticas de discusión de algunos casos especialmente problemáticos en la opinión pública para comprobar si se llega por vía discursiva a la misma conclusión que la mantenida doctrinalmente por el magisterio. No se trata de demostrar la exclusividad de un criterio normativo, sino de mostrar, comprobándola, la vocación de racionalidad en que se funda su discernimiento, con independencia de si es o no mantenido por un imperativo dogmático. Que se pueda argumentar un punto de vista moral, no implica, por supuesto, que sea unánimemente aceptado. El que ese punto de vista sea reconocido tampoco prueba que haya que reconocer la autoridad que lo recomienda. Lo que prueba es si, para su argumentación, ha sido indiferente acudir o no a algún principio de autoridad; o si para justificarlo y haber salido a veces airoso en un debate, basta o no que se valga solo de argumentos ajenos al marco en que tienen una validez preceptiva.

No discutiremos ahora si tiene o no sentido desligar de toda referencia doctrinal una apelación de esta clase, es decir, si un criterio moral, cualquiera que sea, no remite siempre a una doctrina en la que adquiere sentido. Propendemos a considerar que, cualquiera que sea el marco de referencia que se adopte para hacer valer socialmente una regla de moralidad, siempre tendrá sentido con relación a un encuadre doctrinal. Pero nos desentendemos de si, desde este punto de vista son tan doctrinales los marcos de referencia trascendentes como los inmanentes, y de si la única diferencia procede de que el marco trascendente reconoce una fuente de autoridad que no es accesible desde la inmanencia. Y prescindimos de esta posibilidad porque, sea como sea, nada obliga a aceptar la asunción doctrinal de que es preciso limitar a lo privado cualquier recomendación que provenga de una autoridad. Nuestro propósito es otro: tratamos de mostrar si, aunque para muchos la referencia a una autoridad doctrinal solo tenga un valor interno, es decir que solo es válida para quienes la acepten, también hay motivos exógenos a ese magisterio por los que ese criterio merece ser también compartido desde otras perspectivas, encuadres, o marcos doctrinales diferentes, incluidos los que expresamente cuestionen o rechacen esa fuente de autoridad. Para decirlo más rotundamente, si, prescindiendo de cualquier apelación dogmática, las recomendaciones de tal magisterio o autoridad pueden ser reconocidas en su dimensión pública (Casanova, 2000), precisamente porque no es necesario servirse de la referencia a la autoridad para llegar a la misma conclusión mediante argumentos que no la tienen en cuenta. Lo que significaría que ambas vías son compatibles, porque convergen en un supuesto común, se encuentran en un mismo fundamento y comparten un valor de verdad que sirve de condición de compatibilidad en contextos separados ${ }^{8}$.

8 Este planteamiento suscribe explícitamente el análisis de la postsecularización de José Casanova: "Las teorías de la modernidad, las 
El punto de vista expuesto busca, pues, comprobar no solo la relación interna, sino de qué modo ambos compromisos llegan a resolverse en uno solo. Pero, como generalmente, un compromiso requiere una afirmación, no una declaración negativa, es preciso encontrar una respuesta que sea tan objetiva como firme. La fórmula aquí propuesta se basa en la aceptación del criterio de que el valor de verdad de toda información (o afirmación) se determina con referencia a un contexto. Y, si se acepta como hipótesis, la referencia a un contexto trascendente, de lo que se trata es de que la información sea consecuente con ese contexto, lo cual, simplificando la argumentación, implica que esa condición no debe alterar ni condicionar el compromiso de carácter deontológico adoptado en el otro contexto, es decir, el aplicable a las reglas de elaboración o de construcción de un texto periodístico (o histórico), sea una noticia o una opinión.

En trabajos precedentes incluidos en la bibliografía creemos haber probado que la construcción de un texto reclama siempre un marco de interpretación, de comprensión, de verificación o de refutación (Núñez Ladevéze, 1990 y 1994). Estas líneas se proponen ahora precisar algo sobre las condiciones que se han de cumplir para que la verdad del contexto interpretativo trascendente (y, concretamente, evangelizador) sea compatible con la del texto informativo, inmanente, y viceversa ${ }^{9}$.

\section{Contexto trascendente y contexto inmanente}

¿Qué implica, por tanto, este "ser consecuente"? ¿A qué comprometen esos dos distintos contextos? ¿Qué condiciones ha de reunir un contexto trascendente para que sea plenamente compatible con un contexto que, por contraste, podríamos llamar "inmanente"? Las observaciones que siguen a continuación se proponen responder a estas cuestiones.

El periodista cristiano cree en un contexto trascendente. Un contexto que trasciende, pero al que hace referencia, su experiencia del mundo material, el mundo que habitamos como seres humanos, es decir, como criaturas humanas. Importa

teorías de la política moderna y las teorías de la acción colectiva que ignoren sistemáticamente esta dimensión pública de la religión moderna son necesariamente teorías incompletas...(2000: 98) Las intervenciones públicas de la religión en la esfera pública de las sociedades civiles modernas, ya no pueden considerarse simplemente como críticas religiosas antimodernas a la modernidad. Antes representan tipos nuevos de críticas normativas inmanentes a formas específicas de institucionalización de la modernidad que presuponen precisamente la aceptación de la validez de los valores y principios fundamentales de la modernidad, es decir, libertades individuales y estructuras diferenciadas." (299, el subrayado es mío).

9 Hay otros aspectos interesantes relativos al ámbito de la "interpretación”. Martín Algarra distingue "interpretación de la expresividad” de "interpretación de la expresión”. La primera, consiste en "la interpretación del carácter epifánico de los objetos del mundo", trata del "aparecerse de las cosas que nos rodean" y distingue la "interpretación de la expresividad de los objetos naturales" de la "de los objetos artificiales”. Esta clase de "interpretación” queda fuera de nuestro objeto que se limita, en la terminología de este autor, a la "interpretación de la expresión”. La idea de analizar "la interpretación de la expresividad" es sugerente, porque implícitamente viene a distinguir entre mera "percepción” e "interpretación”. Creo que tiene mucho que ver con la noción de "trasfondo" de Searle, pero el autor no las relaciona. También con ideas de Heidegger sobre el carácter epifánico de las cosas. No es el momento de detenernos en esta sugerente propuesta. (Cfr. Martín Algarra, 2003: 149 y ss.) 
reparar, primero, en que ese contexto remite al otro: el trascendente, hipotético, se enuncia desde la inmanencia que se trasciende, que no es hipotética ${ }^{10}$. Segundo, que esa enunciación implica la posibilidad de decir la misma cosa con significaciones e implicaciones distintas, pero no contradictorias, de manera que puede asegurarse que ambos modos puedan ser simultáneamente verdaderos: a saber, seres humanos y criaturas humanas. ¿igualmente verdaderos? Son designativamente coincidentes, pero no sinónimos: no dicen lo mismo, pues no aportan la misma significación. Y la diferencia remite a que el valor de verdad de estas expresiones, "seres humanos" y "criaturas humanas", se comprende con referencia a uno u otro contexto o marco de interpretación, uno de los cuales puede ser invocado, pero también rechazado.

Ciertamente, cabe suponer que nadie objetaría la idea de que somos "seres humanos", pero alguno podría objetar que somos "criaturas". La diferencia está en que, para aceptar como verdadera la expresión "seres humanos", basta con considerar un contexto inmanente, el del mundo desde el que emitimos el enunciado "el mundo material que habitamos", mientras que para considerar verdadera la expresión "criaturas" es necesario interpretarla aceptando un contexto trascendente, aunque no necesariamente el de una fe determinada. Lo que en este trabajo examinamos ahora es cuáles son las condiciones (y si se dan o no esas condiciones) para que la referencia a un contexto trascendente no implique contraponerlo a un contexto inmanente. En realidad, solo se trata de una condición: que nada de lo que sea verdadero en el contexto en que se cumple el rango de validez de la expresión "criaturas humanas" implique negar nada relativo al rango de validez de la expresión "seres humanos". Dicho de otro modo: si se cumple la condición de que nada que sepamos a través de esa doctrina entra en contradicción con lo que podamos saber de nuestro mundo sin tener que recurrir a ella. Eso no significa que el contexto trascendente sea comprensible y no esté inserto en el misterio para la razón humana. Pero tampoco significa que el contexto del misterio sea "fantasmagórico", aunque a veces se utilice esa palabra con alguna ligereza. El “desencantamiento" weberiano del mundo, es decir, lo que de modo equívoco algunos han vinculado al proceso de "secularización”, no tendría que atribuirse la tendencia hacia un desencantamiento de la fe, porque el contexto de la fe, si cumple la condición indicada, inicia ya esa tarea desencantadora al no remitir a un entorno mágico o encantado, sino a un contexto que trasciende el conocimiento que pueda obtenerse, siguiendo la reflexión kantiana, mediante la mera razón ${ }^{11}$. Dicho de otro modo, en un mundo encantado una fe compatible con y orientadora de la razón propicia por sí misma el desencantamiento ${ }^{12}$.

10 Si esta inferencia es válida, como creemos, permite sostener que la iniciativa de la interpretación pertenece al marco de la inmanencia. Los párrafos que siguen se basan en ese supuesto y, a la vez, pretenden confirmarlo. Cabe pensar que algunos componentes básicos de la inmanencia son comunes a toda condición humana, no así los de la trascendencia. Asunto relevante cuando, como es el caso cristiano, se aspira a que ciertos contenidos doctrinales tengan una validez universal, es decir, sean nexos de continuidad entre ambos contextos, por ser accesibles a la mera razón.

11 Planteamiento coincidente en lo principal con el de “desprivatización religiosa” en la postmodernidad propuesto por Casanova: “Lo que yo llamo «desprivatización» de la religión moderna es el proceso por el cual la religión abandona su lugar asignado en la esfera privada y entra en la esfera pública indiferenciada de la sociedad civil para tomar parte en el proceso en curso de debate: la legitimación discursiva y el nuevo trazado de fronteras". (Id. 97) Sobre el debate actual entre "teoría” y "paradigma" de la secularización véase Tschannen, 1992.

12 Lo cual planteó la vuelta a un "reencantamiento" que implica la "desprivatización” de la religión. Para esa revalorización relacionada 
Para la aceptación de la condición expuesta es suficiente atenerse a la reflexión particular de la encíclica Fides et ratio y a otros textos del magisterio como el Catecismo de la Iglesia católica (Núñez Ladevéze, 1996). Como se dijo antes, prescindimos metodológicamente de cualquier referencia teológica o magisterial que presuponga la compatibilidad entre razón y verdad. Para satisfacer las condiciones del propio marco argumentativo esa presuposición habría que comprobarla. Y a ello se dedica la parte de recuento de casos incluida en este texto. No se trata, por tanto, de aceptar o rechazar el argumento doctrinal, sino de verificar si una argumentación inmanentista de los textos de una doctrina puede prescindir de su componente magisterial sin pérdida de su validez: comprobar, a fin de cuentas, si el contexto trascendente de esos textos que hacen referencia implícita a un contexto inmanente, el que sirve para la comunicación entre enunciados de distinto marco, satisface o no las condiciones de validez prescritas en este contexto, el que nos es común en la mera condición de seres humanos.

La relación entre ambos contextos se caracteriza, siguiendo los textos mencionados, por la pretensión de compatibilidad del contexto trascendente ${ }^{13}$ : la hipótesis de que lo que para el hombre no es desde un punto de vista humano, material o naturalmente posible, pueda, sin embargo, ser posible para la omnipotencia divina no es una incongruencia lógica, sino consecuencia de las mismas nociones de plenitud divina y de limitación de las leyes del mundo. No se incurre en una derivación del argumento ontológico mientras alguien se ciña a aceptar las condiciones de uso significativo de las nociones usadas. Para que sea válida en un contexto inmanente la argumentación procedente de un contexto trascendente, el argumento no tendrá que modificar ni contradecir las pautas que nos permiten interpretar racionalmente la experiencia de nuestra pertenencia a un entorno natural, nuestra adscripción a un tiempo y unas circunstancias determinados, el ámbito en el que se inscribe nuestra experiencia cotidiana o su dependencia de una evolución histórica, de un transitar que procede de un pasado y que promueve un futuro indeterminado, por tanto, imprevisible, aunque condicionado por sus precedentes, por tanto, interpretable ${ }^{14}$.

con el uso activo de los medios de comunicación, cfr. Martín Barbero. 1997. El tema se abre a la dispersión. La tesis de una continuidad entre desencantamiento y secularización se mantiene también por teólogos que critican la Ilustración sobre la base de su reemplazamiento por un pensamiento débil, como Tamayo: "Entre cristianismo y secularización no hay ruptura, sino continuidad", que no es equivalente a "entre razón y fe no hay ruptura sino compatibilidad”. De este modo no hay que interpretar la "secularización” como un desenlace del "desencantamiento". (Tamayo, 1995, 21).

13 "La razón posee su propio espacio característico que le permite indagar y comprender, sin ser limitada por otra cosa que su finitud ante el misterio infinito de Dios (14)... No hay, pues, motivo de competitividad alguna entre la razón y la fe: una está dentro de la otra, y cada una tiene su propio espacio de realización (17)... La Iglesia no propone una filosofía propia ni canoniza una filosofía en particular con menoscabo de otras. El motivo profundo de esta cautela está en el hecho de que la filosofía, incluso cuando se relaciona con la teología, debe proceder según sus métodos y sus reglas; de otro modo, no habría garantías de que permanezca orientada hacia la verdad, tendiendo a ella con un procedimiento racionalmente controlable. De poca ayuda sería una filosofía que no procediese a la luz de la razón según sus propios principios y metodologías específicas. Una filosofía consciente de este «estatuto constitutivo» suyo respeta necesariamente también las exigencias y las evidencias propias de la verdad revelada (47)... Fides et ratio.

14 El científico sabe que «la búsqueda de la verdad, incluso cuando atañe a una realidad limitada del mundo o del hombre, no termina 
Para delimitar el tema, cabe añadir a esta prospección algunas precisiones sobre el sentido de la trascendencia en el cristianismo. Como punto de partida, para adoptar una perspectiva definida frente a este panorama inabarcable, asumimos los estudios de Casanova sobre el sentido de la religión en la fase postsecular de la postmodernidad. Para dejar clara nuestra posición interpretativa enunciaremos algunas de las principales asunciones sobre las condiciones necesarias para que una crítica desde una hermenéutica religiosa pueda tener un valor inmanente en una sociedad secularizada ${ }^{15}$. Tales condiciones podrían eventualmente servir de criterios para elaborar tipos, grados y escalas de congruencia entre los postulados presupuestos como condiciones de un orden social pacífico entre discrepantes morales en una sociedad democrática y los postulados dogmáticos de una creencia religiosa.

No toda religión, en el vasto panorama de la multiculturalidad, está en condiciones de poder adoptar una actitud crítica que tenga valor inmanente enunciada desde supuestos trascendentes. Es más, es posible que ni siquiera se lo propongan como un valor constitutivo para la integración en una sociedad plural basada en el supuesto de libertad de opinión y de creencia. Yendo más allá del análisis de Casanova, asumimos que esta relación de compatibilidad racional entre un contexto trascendente y otro inmanente es una pretensión típica (¿cabría decir que exclusiva?), del cristianismo ${ }^{16}$. Ahora veremos brevemente, siguiendo la indagación hermenéutica, cómo y por qué.

La explícita pretensión de racionalidad compromete a que los dogmas doctrinales en que se basa la propuesta de una nueva evangelización sean adecuados o congruentes con nociones inmanentes que han prescindido de esa referencia para fundamentarse. La cuestión está en que la autoexigencia de racionalidad, doctrinalmente postulada, no se cumple de igual modo en cualquier otra religión, de aquí que sea una nota que, al comprometerla, también la distingue significativamente. De la observación de algunos motivos de rechazo procedentes de actitudes laicistas se puede inferir, paradójicamente, que quienes deciden solo admitir (sin más prueba que la que procede de afirmar que la comprobación o verificación empírica es el fundamento de su propia ratio) un contexto inmanente para situar toda apelación a creencias en un ámbito privado, exigen del cristianismo una prueba de compatibilidad con los supuestos de la inmanencia que no se suelen aplicar con el mismo rigor a ninguna otra religión (Núñez Ladevéze, 2005) y, sin embargo, eso es exactamente lo que, desde una interpretación literal, implica la adscripción cristiana. Por último, esos postulados a los que remite el cris-

nunca, remite siempre a algo que está por encima del objeto inmediato de los estudios (106)" Fides et ratio. Para una crítica de este planteamiento, cfr. Panikkar 1994.

15 Para un estudio sobre el proceso de secularización en España cfr. Pérez Agote, 2012.

16 Tema controvertido, sin duda, pero sobre el que hay tanta literatura que hay que renunciar a una exposición. Como botón de muestra nos servimos de una fuente protestante: “Sin el personalismo religioso inyectado en nosotros por el protestantismo y el cristianismo, hubiesen sido imposibles del todo la autonomía, la fe en el progreso... Nuestro mundo afirma conscientemente estas ideas como cristianas de algún modo, y allí donde las niega o ignora lleva, sin embargo, su impronta”. (Troeltsch, 1951: 27). Para este particular nos ceñimos a los trabajos de Werblowsky, aunque el tema es muy discutible y la literatura inabarcable. Para una matizada visión contraria, Panikkar, 2003. 
tianismo para predicar la congruencia entre fe y razón son, no obstante, los mismos en que dijeron basarse quienes rechazan un contexto trascendente cuando tratan de dar razón de los principios normativos del orden y la justicia humana. Más concretamente, que la regulación política, jurídica y moral de la sociedad ha de fundarse en el reconocimiento de dos propiedades de la persona: la libertad de cada uno de sus miembros y la igualdad entre todos ellos, (en realidad se trata de una sola: el reconocimiento de que toda persona es potencialmente tan libre como las demás) ${ }^{17}$.

Ambas propiedades son explícitamente aportadas por la concepción europea u occidental de la vida en sociedad y tienen una honda raigambre, al menos en el sentido que se expone: según la doctrina, la libertad humana permite a cada individuo salvarse y condenarse y esta responsabilidad u oportunidad se aplica indistintamente a individuos de uno u otro sexo, de una u otra raza o condición ${ }^{18}$. Esto significa que, desde ese punto de vista, todos somos responsables de nuestros actos y que cada uno es moralmente autónomo por ser personalmente el sujeto de atribución de esa responsabilidad ${ }^{19}$. A veces se exagera la condición individualista de esta autonomía moral. Pero, limitándonos a una consideración basada en una reflexión empírica, cabría distinguir matizando, porque las simplificaciones dificultan apreciar los matices distintivos, que una cosa es el individualismo sociológico y otra la autonomía moral de la persona (Núñez Ladevéze, L. 2004).

Según el individualismo sociológico, el individuo es la unidad mínima de referencia social. Frente a este generalizado reduccionismo puede objetarse que toda persona moralmente autónoma es un ser o individuo humano, pero no todo individuo humano es, en el mismo grado, persona con autonomía moral. Podría ser así, si la persona no fuese un ser dependiente, pero el hecho es que, desde antes de nacer, ya es heterónoma, y después es, al menos, interdependiente. Toda persona humana es individual desde que es concebida, pero ninguna es al nacer ni física, ni social, ni jurídica, ni moralmente autónoma. Va ganando suficiencia hasta alcanzar la autonomía jurídica y moral, que no siempre todos alcanzan. Se suele decir que todos somos iguales ante la ley, pero, a poco que se piense, se comprende que esta simplificación nunca es plenamente cierta en ningún ordenamiento jurídico. No lo son los nasciturus, ni los niños, ni los desvalidos, ni los an-

17 La expresión "potencial” puede extrañar, pero tiene que ver con la objeción al "individualismo metodológico" que se expone posteriormente. Obsérvese que en la clasificación de modelos expuesta por Panikkar (en Fraijó, 1994: 738 y ss.) no corresponde plenamente al modelo que denomina "liberal", pues comparte rasgos del "metarreligioso" al que, en parte, al menos, corresponde la adscripción de Casanova de la función pública de la religión en sociedades democráticas.

18 No es este el lugar de analizar reservas bien fundadas como el sentido de la expresión extra eclesiam nulla salus. Cfr. Panikkar, 1994: 14 y ss.

19 Aunque Jonas (1996) y otros muchos que no es el momento de citar, expresen fundados recelos sobre el alcance de la "autonomía moral" y resulte obvio que esa autonomía es en todo caso limitada y progresiva en cada individuo, (una cosa es que un lactante pueda llegar a ser un hombre libre y moralmente responsable, y otra que el niño sea moralmente responsable como lo es un adulto), pero no es discutible que la idea de responsabilidad moral individual está ligada al pensamiento de salvación personal: tiene una base cristiana, explícita en la "teología de la salvación". "Se trata de la metafísica del personalismo absoluto que penetra directa o indirectamente en todo nuestro mundo y que presta un cimiento metafísico a las ideas de libertad, de personalidad, de yo autónomo... Esta complexión anímica ha sido establecida por el cristianismo" (Troelchts, id, 26) 
cianos, ni los tullidos. Solo cuando alguien llega a la mayoría de edad legal alcanza el pleno reconocimiento jurídico para la autonomía moral de sus actos. Esto no parece fruto de una ideología particular. Lo cierto y verificable es que no hay legislación alguna que considere a un lactante como sujeto de imputación ${ }^{20}$. El nasciturus y el recién nacido son incondicionalmente dependientes del padre y de la madre. Aristóteles, insistió en que, sin referencia a un principio de cooperación, es imposible entender la subsistencia de las sociedades humanas. Más modernamente, Grice, muestra cómo, sin referencia a un principio de cooperación, no es posible explicar la comunicación mediante el lenguaje. Por lo demás, esa referencia, la aristotélica o la griceana (GRICE, 1957), es pertinente para comprender el sentido de la complementariedad natural entre los sexos (Núñez Ladevéze, 1997).

Centrando el foco ahora en este aspecto concreto... Sin duda, actualmente es posible, a través de técnicas artificiales, la gestación de un niño sin cooperación del varón. Sin embargo, no es posible pensar que la génesis de la sociedad pueda imaginarse o racionalmente deducirse postulando la interacción de un individuo consigo mismo o la copulación entre dos personas del mismo sexo. En suma, un individuo aislado no produce una sociedad. Dos personas del mismo sexo, tampoco, a menos que medie una manipulación artificial o técnica. Por eso, sociológicamente hablando, el individuo no es la base de la sociedad, el átomo social, la unidad mínima de la sociedad, sino la familia ${ }^{21}$. Al menos, que sea una opción argumentable sin quebrar la condición de inmanencia, es independiente de si la enseñanza de la Iglesia viene insistiendo o no en ella desde siempre. Pero nuestra intención es probar cómo el valor de verdad de la autonomía moral no depende de ese adoctrinamiento como tampoco la diferenciación conceptual entre persona moral e individuo humano. De aquí que la afirmación de la autonomía moral de la persona sea diferenciable del individualismo sociológico, pero también del organicismo comunitario, confusión a la que suelen ceder amaestramientos propensos al tradicionalismo, o las nuevas tendencias comunitarias de las que ahora se nutre la ideología colectivista de los nacionalismos exaltados. Si es cierto que un individualismo radical es incapaz de explicar la génesis social, también es cierto que el organicismo comunitario es incapaz de explicar la noción de identidad. Paradójicamente coinciden en zonas donde antaño acamparon, como murallas defensivas frente a la ilustración liberal, los idearios tradicionalistas y la defensa del viejo régimen frente al liberalismo ${ }^{22}$.

El concepto de "identidad" tiene un sentido definido. Dos cosas son idénticas cuando son iguales entre sí. Aplicando el principio leibniziano de los "indiscernibles" habría que concluir que solo la persona es idéntica a sí misma, y que, hablando de seres humanos, la identidad es una noción que solo se predica sustantivamente de la persona y metonímicamente de cualquier otra relación. Por definición, los miembros de una organización social no son idénticos

${ }^{20}$ A menos que se le impute pertenecer a una casta, a una familia o a un clan. Pero justamente eso es lo que se rechaza en el principio de autonomía.

21 He argumentado este planteamiento en Núñez Ladevéze, 2000.

22 Para una crítica del organicismo, puede verse J.A. Gallego 2007: 697 y ss. Sobre la relación entre "nacionalismo" como sustituto secularizado del “organicismo" religioso (aunque no usa esta expresión), cfr. Santiago García, 2004. 
entre sí, no son clones, ni productos en serie. El coincidir en o compartir una misma tradición, sentimientos, lenguaje o etnia no significa poseer una misma "identidad" a menos que se adopte el significado de "identidad" en un sentido traslaticio como hace el DRAE en la segunda acepción de un artículo enmendado para la última edición. Pero la diferencia conceptual no queda eliminada por la enmienda. La palabra para distinguir nocionalmente un concepto de otro podría ser "idiosincrasia" que se refiere a compartir rasgos o signos

Volvamos, para cerrar el tema, a la relación entre el contexto trascendente y el inmanente, en el que se sitúa la cuestión de cómo han de proceder los comunicadores en el "contexto de la nueva evangelización". Tras abordar en concreto esa relación queda ahora bosquejada como una compatibilidad racional de contextos diferentes. Contrastada la hipótesis de la compatibilidad entre ambos contextos y advertido que los principios nucleares de igualdad y libertad, autonomía y persona son compartidos por ambos, se puede aceptar como muy razonable la proposición de que históricamente han sido promovidos por la propia visión cristiana (hemos citado a Troeltsch solo por personalizar el punto de vista en algún historiador solvente y por encima de la sospecha doctrinal de quedar condicionado por la tarea de la "nueva evangelización" $)^{23}$, porque esto es algo que suele ser discutido, incluso rechazado, por algunas ideologías. Resulta extravagante que, dando un giro de tuerca, insospechable antes de la caída del muro de Berlín, sea la postmodernidad la que ahora ponga en duda la universalidad de esos conceptos de libertad e igualdad de las personas. La ponen en entredicho concepciones relativistas, multiculturales y nihilistas nacidas de la descomposición de la tradición intelectual ilustrada. Resulta, entonces, paradójico, pero es así, que actualmente sea la "nueva evangelización", con su referencia trascendente, una nueva garantía para la aceptación, desde una perspectiva inmanente, de la autonomía de la persona y de la igualdad entre todas ellas ${ }^{24}$. Tal vez, ese arraigo en lo sustantivo tenga que ver con que, a la postre, la ilusión haya tenido más porvenir que las predicciones de quienes la calificaron de ilusoria.

Sin entrar en el debate concreto, esas concepciones ponen en cuestión los supuestos que durante toda la Ilustración, incluida la más beligerante para con el catolicismo, se propusieron como axioma. Paradójicamente, la afirmación de respeto, de reconocimiento, de culturas ancestrales, acaba situando en condiciones de igualdad todas las tradiciones culturales sin

23 Supra nota 11. Para la autocomprensión de esta idea en la "nueva evangelización”: “...38. Abatidas las barreras raciales, sociales y sexuales, el cristianismo había anunciado desde sus inicios la igualdad de todos los hombres ante Dios. La primera consecuencia de esta concepción se aplicaba al tema de la verdad... 76. Incluso la concepción de la persona como ser espiritual es una originalidad peculiar de la fe. El anuncio cristiano de la dignidad, de la igualdad y de la libertad de los hombres ha influido ciertamente en la reflexión filosófica que los modernos han llevado a cabo." Carta encíclica Fides et ratio. Enlace en http://www.aciprensa.com/Docum/fideter.htm

El tema es muy controvertido y aceptamos el riesgo de adoptar una línea de interpretación, entre otras. Puede verse una reciente aportación al tema en Cerezo, 2010, donde se analiza la pretensión de Blumenberg de juzgar la modernidad como una "nueva fundación sobre motivos inmanentes a la autoconciencia del hombre".

24 "El diálogo entre los creyentes de las diversas religiones quiere ser una contribución a la paz, rechaza todo fundamentalismo y denuncia toda violencia que se produce contra los creyentes y las graves violaciones de los derechos humanos.” Cfr. Ratzinger, J. (2001) 
tener en cuenta sus distintas fundamentaciones y sin sopesar las implicaciones del principio de reciprocidad para establecer la simetría en la relación entre identidades, creencias, culturas, etc.: si alguien reconoce al otro, el otro ha de reconocerme a mí. Y eso implica determinar un sustrato común que permita reconocer al otro como equiparable a mí para que ese reconocimiento pueda ser recíproco ${ }^{25}$. Si no es así, no puede haber equiparación entre culturas distintas. Una reconoce a la otra más de lo que la segunda está dispuesta a reconocer a la primera. Esta disimetría conculca el supuesto de racionalidad. La consecuencia es que si no hay reconocimiento de la dignidad de cada persona, es decir, de su libertad moral, no se puede establecer esa condición. Dicho de otro modo, la lógica que implica un mutuo "reconocimiento" puede actuar como patente que distingue a una cultura entre las demás (Núñez Ladevéze, 2007).

Fijemos ahora la atención, para concluir esta parte, en despejar un prejuicio muy frecuente que a veces se expone como argumento en el inmanentismo como prueba de incompatibilidad entre presupuestos de la ciencia, producto ilustrado, y los presupuestos doctrinales cristianos. Según esta argumentación, como la creencia es un dogmatismo doctrinal, no puede esgrimirse frente a proposiciones científicamente probadas.

Para simplificar nos servimos de un texto de Gadamer: es condición del progreso del conocimiento científico que nada de lo que está escrito en su ámbito de referencia tiene por fin quedar definitivamente establecido. Por su propia naturaleza, el conocimiento científico es relativo, acumulativo y parcial. Por supuesto, pasa por pruebas de consistencia, en especial, la metodología aplicada a la comprobación y refutación de tesis e hipótesis, lo que garantiza que vaya progresando, que se vaya renovando y rectificando sobre bases objetivas, y no subjetivas, porque los procedimientos de validación, refutación y prueba son independientes de la subjetividad, comprobables empíricamente por su éxito o su fracaso, por la utilidad práctica de su valor añadido. De aquí que sea poco útil discutir las aportaciones de la ciencia. Quien lo haga quedará en situación de desventaja respecto de quienes aceptan la eficacia del instrumento.

Esto no significa que la ciencia tenga la "última palabra", que su progreso agote su sentido en sí mismo, sino transformándose en instrumento de otro fin más amplio que trasciende a la ciencia misma, por ejemplo, una finalidad humanística o una concepción moral del hombre y de la persona. El valor social de la ciencia es tan racional como instrumental y los científicos no se distinguen por su amor a la verdad más que los demás. En eso se basaba Feyerabend (1982) para exigir un control social y democrático de los científicos y de sus aplicaciones. Parafraseando a Gadamer, "mal científico el que crea que puede o debe quedarse con la última palabra"26. La ciencia es un instrumento sine qua non para la reproducción de una sociedad compleja cuya supervivencia requiere medios de eficacia específica. Pero la condición del científico ha

\footnotetext{
25 El principio de reciprocidad está relacionado con el concepto de "denominación" que Niehbur (1954) aplica a aquellas organizaciones religiosas que consideran en pie de igualdad a otras y que no amenazan a sus miembros porque cambien de credo. (Cfr. Hills, 1976, 71 y ss.)

26 “...mal hermeneuta el que crea que puede quedarse con la última palabra”. Gadamer, 1975: 673.
} 
de ser congruente con la obviedad de que la última palabra, suponiendo que la haya, no puede estar al alcance de ningún conocimiento renovable. Es más: justamente si la ciencia fuera la última ratio de un texto, si hay alguna última palabra, tendrá que pertenecer a un contexto que trascienda al texto que se proponga enunciarla.

\section{Utillaje analítico}

Ciñéndonos al examen de la propuesta del "papel de los comunicadores en el contexto de la nueva evangelización", no hace falta añadir que la expresión "evangelización" remite a un contexto trascendente. Lo que hay que asegurar en el análisis del caso es que si se cumplen las condiciones de coincidencia en una misma noción del valor sustantivo de la libertad personal, no haya nada que impida a un texto comunicativo que sea verdadero en un contexto histórico para que sea, a la vez, válido en ese contexto que lo trasciende. Esta es una interpretación de la relación entre verdad inmanente y verdad trascendente que puede aportar luz sobre el modo de afrontar la tarea de los comunicadores de modo que sean consecuentes con las exigencias de informar sobre las circunstancias de la actualidad o verdad concreta en un contexto restringido sin que eso signifique renunciar a la verdad contextual, aunque esas noticias perjudiquen o aparenten hacer daño a la institución en que confían. Porque si la institución en que confían no es consecuente con sus presuposiciones sustantivas, o no es fiable, o tendría que rectificar en lo que no lo sea.

El análisis del caso no pretende tener un valor demostrativo, solo mostrativo, se trata de comprobar, no de demostrar. Para entender bien el exacto sentido que damos a la descripción de casos que a continuación se exponen es conveniente adelantar una distinción cuyo alcance no podemos aquí justificar plenamente. Estamos razonablemente seguros de su pertinencia, pero no de su aplicación general, que requeriría ajustes para distintos tipos de construcciones de significado. Distinguimos, a estos efectos, entre marco de interpretació $n^{27}$ (de una unidad significativa: una proposición por ejemplo moral, un enunciado científico, o viceversa), que es el contexto de referencia en que el enunciado cobra su sentido; rango del marco (los marcos forman parte de un sistema significativo o contexto de interpretación cuyo niveles se incluyen uno en otros: por ejemplo, un matrimonio religioso ocupa un rango dentro del marco de las instituciones comprendidas por el conjunto de una religión) y pretensión de validez de un enunciado asignada en un marco que puede ir o no más allá del marco de asignación: (por ejemplo, si a un enunciado moral se le asigna validez en un marco científico, o, al revés, se pretende deducir un enunciado moral a partir de un marco científico; si hay que establecer condiciones para que un matrimonio civil haya de tener o no reconocimiento en un marco religioso, o viceversa).

Esta distinción se apoya en una teoría de la significación (comprensión de un signo o un conjunto organizado de signos entendido como unidad significativa), y de la interpretación (sentido que adquiere un signo o un conjunto en uno u otro

${ }_{27}$ Las fuentes bibliográficas para la noción de "marco" son numerosas. Como referencia principal. Goffman, 1986. 
contexto, de modo que un signo complejo actúa como contexto de un signo más simple) ${ }^{28}$. La distinción remite a una elaboración sistemática de rangos, marcos, pretensiones y contextos que sea consistente en una teoría explicativa de la construcción social del sentido, de las normas y de las instituciones, entendidas como fenómenos de atribución y distribución del significado en sus correspondientes contextos. Nos inspiramos principalmente en Searle 1997, aparte nuestra contribución (Núñez Ladevéze, 1994 y 2005), de fuentes hermenéuticas (para esta aportación, principalmente GADAMER, 1977) y de crítica de la ciencia y del método científico (Feyerabend, 1981 y 1982). La distinción es relevante entre otras cosas para comprender el alcance del principio de reciprocidad entre creencias al que antes se aludió.

Pondré ejemplos de aplicación de la distinción: el dogma de la Inmaculada Concepción tiene sentido en el marco de una doctrina trascendente y ocupa un rango en ese marco. La pretensión de validez de esa creencia puede aspirar a convertirla en imperativo fuera del ámbito o marco de aplicación donde adquiere sentido. Si es así, quebranta el principio de simetría. Otro: la obligación de ayunar ciertos días de Cuaresma tiene sentido en su marco y ocupa un rango en su reglamento, la pretensión de que ayunen quienes no comparten la creencia o el reglamento en que se funda queda fuera del marco donde cobra sentido. Otro más: los musulmanes no comen carne de cerdo como consecuencia de un imperativo moral de su marco reglamentario, pero se abre una polémica cuando en un colegio laico francés algunos padres musulmanes pretenden que se suprima la carne de cerdo en la comida. Esta distinción puede trasladarse a cualquier otra institución ${ }^{29}$.

28 Se distingue la comprensión de unidades significativas de la interpretación contextual. Comprender e interpretar son niveles escalonados e interdependientes de una misma tarea. Según la semántica lingüística y la teoría de texto cualquier unidad significativa se comprende a partir de sus componentes con exclusión de que la unidad forme parte de otra unidad, es decir, que, a su vez, sea un componente. Por ejemplo, una palabra, "sentido", se comprende como unidad significativa con relación a la lengua, pero se interpreta si forma parte de un sintagma: "el sentido de la palabra 'sentido', en la frase "el sentido del olfato" no tiene el mismo sentido que en la frase "esta persona no tiene sentido". En este caso, se trata de la diferencia entre "significado" de lengua y "matiz" o acepción significativa en la frase o en la situación comunicativa. La frase "este hombre carece de sentido" es una unidad de sentido. Como fuente teórica de esta distinción, semántica estructural y teoría del texto aparte, puede servir esta cita: "Yo soy renuente a usar la palabra "interpretación”, pues sugiere algo que es definitivamente falso. El uso de esta palabra sugiere que, siempre que entendemos algo o que percibimos algo, hay un acto de interpretación. Por descontado, yo no quiero decir eso. Lo que trato de decir es que normalmente nosotros nos limitamos a ver un objeto o a entender una sentencia sin que medie acto alguno de interpretación. Producir un acto de interpretación constituye una prestación intelectual muy especial. Siguiendo a Wittgenstein, yo podría reservar la palabra “interpretación” para aquellos casos en que ejecutamos realmente un acto consciente y deliberado de interpretación, como cuando, por ejemplo, sustituimos una expresión por otra" (Searle, 1996: 145). Searle remite al parágrafo 201 de Investigaciones filosóficas. Pero véase también este otro: "Por supuesto a veces interpreto signos, les adjudico una interpretación; pero eso no sucede siempre que comprendo un signo. (Si alguien me pregunta '¿Qué hora es?' no hay un laborioso proceso interno de interpretación: sencillamente reacciono a lo que veo y oigo" (Wittgenstein, 1988, § 35). Para un análisis de la diferencia entre "comprender" e "interpretar" puede verse "El paso simbolizador de Searle” en Núñez Ladeveze, 2005: 223 y ss. Para un análisis más detenido Núñez Ladeveze, 1993 Y 1994.

29 Es aplicable a los marcos teóricos y científicos que también pueden aspirar a pretensiones de validez fuera de su marco: "La ingenuidad de la manera habitual de hablar de la 'objetividad' que excluye por completo a la subjetividad que experimenta y conoce, a la 


\section{Casos de discusión}

Pueden comentarse ahora algunos casos de gran difusión en que se pudo plantear problemáticamente la relación entre el marco interpretativo y la pretensión de validez. Esta práctica, planteada de diversas maneras, fue objeto de seminarios con alumnos de doctorado entre los que, en varias ocasiones, había periodistas ejercientes. Se puso a discusión hasta qué punto un periodista católico estaría obligado, por mor de la verdad, en este caso la imparcialidad informativa, a informar sobre la pederastia del clero en Irlanda y en Estados Unidos, o debería evitar dañar la imagen de la Iglesia. Tras discutir el asunto, el criterio concluyente fue que "está obligado", y a aceptar el principio de proporcionalidad informativa profesionalmente regulado: no exagerar ni tampoco ocultar. Lo cierto es que la Iglesia acabó aprobando que el perjuicio que esas informaciones podían causar a su imagen institucional no podía servir de argumento para encubrir las informaciones. Iglesia y pederastia, desde un punto de vista informativo, pertenecen al marco de la información y no es admisible que ninguna pretensión de validez de otro marco puede interferirse. El Papa Benedicto XVI lo confirmó como principio asumiendo que la regla de validez correspondía al marco de la información.

Se discutieron otros casos como cuando el Papa Benedicto XVI pidió perdón por las Cruzadas o por la Inquisición. Cuestiones más discutibles que la anterior, porque es difícil situarse en el contexto histórico para comprender lo que significaron en su momento. Pero está claro que, para mantener la coherencia del propio contexto de la trascendencia con la libertad personal, habrá que asumir que la fe no puede imponerse por las armas, ni que un castigo material o físico pueda servir de garantía de profesión de la fe. Lo cual coincide con lo que cabe concluir si se aplicara al historiador un criterio de deontología profesional.

Se puede obtener una primera inferencia: si la verdad de las cosas que acontecen es verificable o refutable (salva la alusión a la omnipotencia), la información, sea histórica o de actualidad, no puede quedar supeditada a una creencia. Lo que importa respecto del contexto de evangelización es que su pretensión de validez no altere los criterios deontológicos aplicables a la actividad informadora. La compatibilidad se pudo comprobar también en otras sesiones de seminario en las que, por regla, se excluyeron apelaciones a la autoridad o argumentaciones dogmáticas para defender posiciones coincidentes con proposiciones propuestas habitualmente como verdaderas por el magisterio eclesial. A continuación se exponen algunos ejemplos.

En un seminario de doctorado se discutió sobre los "matrimonios homosexuales". Algunos mantuvieron la posición de que la palabra "matrimonio" era inapropiada, otros inaceptable, otros que adecuada. Un punto de vista particular sugirió

única que produce de una manera verdaderamente concreta, la ingenuidad del científico de la naturaleza y del mundo en general que es ciego para el hecho de que todas las verdades que él gana como objetivas y aún el propio mundo objetivo que es el sustrato de sus fórmulas, es el constructo de su propia vida, que se ha formado en él mismo; esta ingenuidad deja de ser posible en cuanto se introduce la vida como objeto de la consideración." (Husserliana, VI, 99. citado por Gadamer, I, 313) 
que el problema de fondo es de diferente cariz: el de la trivialización del sexo, la extendida presunción de que las relaciones sexuales no tienen trascendencia moral, o de que los cambios de sentimientos afectivos, que por definición son transitorios, pueden justificar cualquier relación o conducta sexual.

Planteada así, la cuestión de las palabras pasó a ser asunto menor ${ }^{30}$ y el debate se centró sobre un aspecto más genérico: la tendencia a tratar las relaciones sexuales, en especial las prematrimoniales, como una opción sin trascendencia moral. Algunos las rechazaban, pero a la mayoría no les parecía importante. Tras recapacitar sobre la tendencia a adoptar en el plano moral el principio del menor esfuerzo, un alumno, periodista profesional, se proclamó homosexual. Le disgustaba el planteamiento de la trascendencia moral de las relaciones sexuales, porque le condicionaba más de lo que le gustaría, pero admitía que, al menos, dijo, le situaba en un plano moral de mayor igualdad con los demás. "Comprendo que cumplir un compromiso es preferible a la promiscuidad y acepto estar tan obligado como los demás por la lealtad", aseguró. La cuestión es que no hizo falta apelar a ninguna autoridad para concluir que las relaciones sexuales inestables no eran moralmente equiparables a las estables y que las de fuera del matrimonio no eran equivalentes a las de los casados.

En otras ocasiones, el debate pasó a distinguir entre lo que algunos presentaban como una cuestión de "derechos", y, otros, de "moral". Se argumentó que no se trata de "derechos", palabra que se usa frecuentemente de un modo que entorpece la discusión. Jurídicamente hablando todo derecho subjetivo ha de estar delimitado para que pueda ejercerse o reclamarse su restitución mediante alguna reclamación. Aceptada la enmienda de que no se discutía sobre el derecho a las "relaciones prematrimoniales", sino sobre la libertad para relacionarse de un modo o de otro sin temor a que nadie lo impida, pasó entonces a discutirse la pretensión de equiparar moralmente la relación entre un hombre y una mujer para formar una familia y la de dos hombres para establecer una relación sexualmente estable y devengar los derechos legalmente reconocidos como inherentes a esa relación. Para unos la relación era asimétrica y para otros las situaciones deberían ser equiparadas. La mayoría pensó que la relación de un hombre y una mujer para formar una familia tenía más visos de permanencia que la homosexual. Y para llegar a una conclusión que fue aceptada como la más razonable, no hizo falta apelar a ninguna autoridad.

30 Un punto de vista "particular" arguyó que la Iglesia hace ya tiempo había aceptado tácitamente una terminología que ahora rechaza al no reparar en que la palabra "matrimonio" se aplicaba indistintamente al canónico y al civil. Si el primero es incompatible con el divorcio y el segundo, compatible, ya no sería el civil un "matrimonio", al menos no debería serlo para la Iglesia, por no ser un vínculo indisoluble y permanente. Si, para la Iglesia, el "matrimonio" es permanente, la unión civil entre sexos distintos ya no lo es. Pero la Iglesia no objetó que se utilizara la palabra "matrimonio" para la unión civil, tal vez porque hubiera sido inútil, pues el uso moderno de la palabra "matrimonio" está vinculado a la institución civil tanto como a la canónica. El vicio ya estaba, por tanto, en su origen, y ahora le ha resultado inevitable aceptar el uso legal de la palabra "matrimonio" para situaciones que no son vínculos permanentes entre personas de distinto sexo. En suma, pasó el tiempo para la Iglesia de objetar el uso de las palabras, pero no el de discutir sobre el fondo de la cuestión. 
En otro seminario se discutió si ser consecuente con la pretensión de que las relaciones sexuales son moralmente inocuas, como se propone en textos que se presumen pedagógicos ${ }^{31}$, podría llevar a admitir como normales, indiferentes o deseables, situaciones absurdas o grotescas. Para ilustrar la equiparación, el director del debate propuso comentar en otras sesiones el sentido de La cabra o ¿quién es Silvia?, una obra de teatro de Edward Albee, un dramaturgo norteamericano de la tendencia naturalista de Tenessee Williams.

El debate desechó que la obra fuera un ejemplo de teatro del absurdo y la clasificó como un drama sobre la incomunicación humana que lleva hasta el extremo un argumento o una actitud frecuentemente asumida: la del "todo vale" cuando se trata del vínculo entre sentimientos y relaciones sexuales. Dicho de otra manera, si, salvando los matices que pueden justificar o explicar cada caso en su contexto, valiera lo mismo el hogar de un matrimonio estable basado en la lealtad mutua, que el de unos divorciados o el de una pareja homosexual, entonces también valdría lo mismo (tal fue la interpretación más aceptada sobre el sentido de la trama urdida por Albee) enamorarse de una cabra, que de un rinoceronte, o que un padre formara pareja con su hijo o con la primera o el primero que pasasen por la esquina. Se convino en que Albee no presenta una moraleja, describe una situación anómala a la que aplica las pautas de corrección moral imperantes, y es al espectador a quien corresponde la tarea de llegar a una conclusión. Lo que Albee dramatiza lleva a sus consecuencias extremas el criterio de que los sentimientos afectivos pueden justificarlo todo. El seminario concluyó que la equiparación del amor de un hombre por una cabra y el amor de un hombre y una mujer para constituir una familia es una reductio ab absurdum de un sentimiento dominante.

Volviendo al tema de la pederastia. En el seminario se arguyó que si las tendencias de los niños no han de ser reprimidas ¿por qué lamentar la pederastia si puede interpretarse como una práctica liberadora de la represión? Puede resultar exagerado llevar el argumento hasta ese extremo, como se hizo en el debate, pero la reductio ab absurdum contribuyó a aclarar que si un punto de vista puede llevar al absurdo el argumento que lo hace patente es un buen argumento, independientemente de que coincida o no con la doctrina moral patrocinada por una religión. En consecuencia, tampoco se trata, porque se acepte como creencia, de no informar sobre la pederastia de los clérigos, sino de que informar sobre casos de pederastia puede perjudicar a una creencia si trata de encubrirlos para no dañar su reputación social. La conclusión fue que aplicar consecuentemente el principio de que informar sobre la pederastia no necesita del respaldo de ninguna autoridad.

El asunto en suma es: la verdad evangélica pertenece al contexto interpretativo de la última palabra, al contexto implicado por la hipótesis trascendente, pero no pertenece al marco del comunicado. Es la perspectiva desde la que se enfoca la información, la que debe inspirar a los comunicadores e informadores, sean o no cristianos. En el caso del informador cristiano, los comunicadores están comprometidos a adoptar una actitud que pertenece al contexto evangelizador, pero

31 Se citaron algunos de la asignatura Educación para la ciudadanía. 
que no les libera de aplicar las reglas profesionales de elaboración, selección y ponderación de los textos comunes al ejercicio de la profesión. Por lo demás, ni siquiera debería tener sentido planteárselo si en las pretensiones de validez del marco trascendente se sustenta, como se dice, en una noción natural, empírica, de responsabilidad moral, ya que tal noción presupone asumir el marco inmanente al valor de verdad de la información.

Tanto en estas como en otras sesiones se comprobó que no era necesario acudir a ninguna fuente para llegar a las mismas o similares conclusiones que las propuestas por el magisterio siempre que la pretensión de validez del marco magisterial aceptara como medida de su pretensión la aplicación de las reglas de validez del marco en que quisiera hacerse valer. Pero de ahí se desprende otra conclusión que tiene que ver expresamente con la expuesta por José Casanova en la exposición de su tesis sobre la dimensión pública de las religiones modernas cuyas reprobaciones morales tienen el valor de "críticas inmanentes a formas particulares de la modernidad desde un punto de vista religioso moderno" (2000: 299).

Concluimos: para que la crítica religiosa pueda ser a la vez "inmanente” a los postulados de la tradición ilustrada, es necesario que el contexto de la trascendencia comparta los postulados básicos del contexto inmanente y que la pretensión de validez de la crítica se ciña a las reglas del marco en que trata de ser válido. El hecho de que se sirva de la base argumental de los enunciados que critica sin ponerlos en cuestión, prueba que no hay incompatibilidad interna entre los dogmas religiosos y los fundamentos de un marco inmanente de verdad (de libertad, de igualdad de la persona, etc.) No son zonas impermeables. De otro modo, no cabría que se pudiera llegar a la misma conclusión que una crítica religiosa si se prescindiera de referencias dogmáticas o de autoridad. Pero tampoco hay que pedir a la crítica religiosa que renuncie a ellas, si permiten mostrar cómo las condiciones de validez que se ciñen al propio marco contribuyen a aclarar las motivaciones, el origen o la pauta de los argumentos o centrar el sentido de mensaje para quienes comparten las reglas establecidas en ese marco.

\section{La novedad en la tecnología}

La cuestión sobre si la apelación neoevangelizadora compromete o no la objetividad informativa por implicar un marco dogmático tiene respuesta. Pues si el enfoque para el periodista abarca todo cuanto puede ser razonado sin necesidad de recurrir a argumentos doctrinales asumidos por decisión de una autoridad, lo relevante es que no se necesite apelar a ese magisterio para llegar a las mismas conclusiones, en especial en asuntos sobre los que, por hondos que sean los motivos de discrepancia, solo pueden dirimirse desde un trasfondo participativo que asegure la racionalidad de la discusión sobre los valores comunes o universales de la condición humana. Volviendo a una observación precedente, si postulamos la posición del "velo de la ignorancia" de Rawls, tal vez no cabría invocar una pareja homosexual como génesis natural de una sociedad humana. El informador no necesita apelar al magisterio más que como cautela o guía para adoptar una perspectiva o actitud que puede ser concordante por quien no comparte su creencia. 
Para satisfacer un último aspecto de la tarea de analizar las implicaciones que supone a un periodista presto a servir a la advocación de la "nueva evangelización", cabría enfocar la lente del comentario en el vocablo "nueva" del sintagma enunciado. Entre los distintos aspectos que pueden quedar comprendidos en la expresión "nueva", hay uno explícito en el que nos detendremos sucintamente para dar punto final a esta exégesis ${ }^{32}$.

Hay varias sugerencias contenidas en la reflexión sobre la "novedad" de la noticia evangelizadora. La primera es que se trata de algo permanente. En este sentido, hay un motivo pesimista en el hecho de que haya que promover una "nueva evangelización": que actualmente sea más necesario esforzarse en comunicarla, que sea preciso "renovarla", porque esa "buena nueva" haya perdido el brío, la fuerza de su origen, a causa del proceso de "secularización” del mundo occidental y de la convivencia de tradiciones culturales no siempre equiparables. Este entendimiento de la "nueva evangelización” está expresamente asumido en los documentos y ya tramitado en lo expuesto antes sobre el sentido del proceso de secularización de la sociedad cristiana. Ya hemos advertido como aspecto singularmente novedoso, que actualmente no se discute el texto, sino también el contexto, que ya no hay un lugar de encuentro, por muy controvertido que sea, como pudo haber durante la Ilustración una convergencia, aunque se divergiera en las interpretaciones, sobre el significado y los fines de procurar la libertad e igualdad humanas que impulsaron su proceso. En este ambiente de abandono o de claudicación de la modernidad de su seña originaria, puede ser paradójico que sea la "nueva evangelización" donde se ice la bandera para acometer esa función integradora.

Hay otro aspecto de la "novedad" contenido en el uso de la expresión "nueva" en el llamamiento a una "nueva evangelización” que está relacionado con la asunción de esa tarea de fijar un lugar de encuentro en la multiplicidad de las culturas y la aleatoriedad de las perspectivas. Se trata de la expresa acogida de los nuevos medios de comunicación como instrumentos adecuados para contribuir a esa labor evangelizadora ${ }^{33}$. Este es el último aspecto por queda por atender, el que mejor corresponde a la condición de un estudioso de los medios de comunicación social. Repararemos solo en la ambivalencia de los efectos de la “democratización de la comunicación” (Núñez Ladevéze, 2012). Los lamentos por la trivialidad de los contenidos especialmente del entretenimiento no son ocasionales. Aunque ahora no es momento de detenerse en

32 Para completar el sentido de la expresión “nueva evangelización” en el magisterio de Benedicto XVI, cfr. "La nueva evangelización para la transmisión de la verdad cristiana” Liberia editrice vaticana. Ciudad del Vaticano, 2011.

33 "Estudiar y favorecer el uso de las formas modernas de comunicación, como instrumentos para la nueva evangelización". A 3.4. Ubicumque et Semper. (Benedicto XVI, 2010).

"Las vías de comunicación abiertas por las conquistas tecnológicas se han convertido en un instrumento indispensable para responder adecuadamente a estas preguntas, que surgen en un contexto de grandes cambios culturales, que se notan especialmente en el mundo juvenil. En verdad el mundo digital, ofreciendo medios que permiten una capacidad de expresión casi ilimitada, abre importantes perspectivas...El desarrollo de las nuevas tecnologías y, en su dimensión más amplia, todo el mundo digital, representan un gran recurso para la humanidad en su conjunto y para cada persona en la singularidad de su ser, y un estímulo para el debate y el diálogo. Pero constituyen también una gran oportunidad para los creyentes. Ningún camino puede ni debe estar cerrado..." Mensaje del santo padre Benedicto XVI para la XLIV jornada mundial de las comunicaciones sociales:16 de mayo de 2010. 
este particular, no es dudoso que el transcurso de la "secularización" está ligado al cambio de los hábitos sociales condicionado por la renovación de los medios de comunicación. La posibilidad de difundir cualquier información, el acceso indiscriminado a todas las bases de conocimiento o de desconocimiento, promueve la equiparación en la apreciación social de los rangos del saber, igualando los criterios de credibilidad, desdibujando la diferencia entre las fuentes de autoridad. Que las nuevas tecnologías sirvan de instrumento de equiparación o de propagación de cualquier punto de vista, que acoja en igualdad de condiciones cualquier criterio de moralidad, forma parte del ambiente de labilidad, propio del conformismo nihilista y característico del relativismo moral que desde la perspectiva de la nueva evangelización "ha verificado una pérdida preocupante del sentido de lo sagrado, que incluso ha llegado a poner en tela de juicio los fundamentos que parecían indiscutibles”34.

Ya que los medios comunicativos pueden multiplicar los estragos del proceso secularizador cabría razonablemente esperar una actitud de reserva hacia su uso. Si fuera así, la actitud no sería aislada. Son muchos los intelectuales prestigiosos que reprueban las nuevas tecnologías ${ }^{35}$. Las advertencias de los riesgos derivados del acceso indiscriminado a internet son constantes. Por poner un ejemplo de la equivocidad, esta sociedad nuestra, occidental, es la que más se preocupa por asegurar un marco de protección del menor para defenderlo de los excesos de la transmisión de contenidos en los medios de comunicación e instrumentos similares, como videojuegos, móviles, consolas, etc. Y es también la que más se queja por los resultados de sus propias medidas. El asunto es simple: las propuestas enfocadas a enderezar la situación alimentan los estudios que describen un panorama preocupante. Esa paradójica combinación invita a reflexionar sobre si no habrá algún aspecto que escape a las previsiones y a los reglamentos. ¿ No cabe pensar que la estabilidad de la infancia, por fijar la atención en un tema sensible objeto expreso de la atención institucional de la agenda europea, no depende solo de las políticas desiderativas derivadas de preconcepciones ideológicas, que nadie discute y que todos aceptan? El problema, entonces, puede que esté en otro lugar: ¿por qué los niños necesitan ser especialmente protegidos si hay un consenso institucional y social sobre la necesidad de protegerlos? ¿Qué pasa para que, estando de acuerdo en aceptar iniciativas protectoras, sea constantemente necesario insistir sobre la insuficiencia de los métodos destinados a la protección? ¿Hace falta acaso una encuesta diaria para cerciorarnos de que los niños necesitan más medidas protectoras de las acordadas tras la encuesta anterior? (Torrecillas, 2011)

Al final del trayecto habría que admitir que nos hallamos ante una desviación moral que ha desbordado el proceso secularizador, un riesgo cuya cura no está, obviamente, al alcance de los remedios que se invocan. Sin embargo, lo que expresamente se advierte, exhortando al uso de los medios en la apelación a una nueva evangelización, es que el problema no procede del instrumento, aunque no sean pocos quienes, apelando a estas razones, los rechacen. Desligar la informa-

\footnotetext{
34 Benedicto XVI, Carta Apostolica Ubicumque et Semper.

35 Tentación abierta al intelectual. Como muestra puede acudirse al Homo videns de Giovanni Sartori.
} 
ción de un periodista que se proponga ser consecuente con la propuesta de nueva evangelización de cualquier directriz del magisterio sobre cómo ha de elaborar, abordar o presentar una noticia, es una derivación inherente a la confianza de que el contexto de la trascendencia no entra en conflicto con la razón moral. Pero las virtudes públicas son como los deseos, tienen validez desiderativa y, parodiando a Hume, ya debería saberse que de un deseo, aunque se haya elevado a precepto público, no se puede deducir una conducta responsable. Lo paradójico es que, habiendo unanimidad práctica y coincidiendo en la necesidad de prevenir los riesgos y patologías inherentes a los usos de la nueva tecnología, la enfermedad prospere cuantas más medidas terapéuticas se administran ${ }^{36}$. Pero el quid radica en que, en el diagnóstico de que la causa no está en el medio, coinciden tanto quienes administran la inútil terapia como los promotores de una "nueva evangelización”.

\section{Referencias bibliográficas}

Baubérot, René (2007): Les laïcites dans le monde. Paris: PUF

Benedicto XVI (2010): Carta apostólica en forma de «motu proprio» UBICUMQUE ET SEMPER que instituye El Consejo Pontificio para la promoción de La nueva evangelización. Castegandolfo. Disponible en: http://www.vatican.va/holy_father/benedict_xvi/apost_letters/documents/hf_ben-xvi_apl_20100921_ubicumque-et-semper_sp.html http://www.vatican.va/holy_father/john_paul_ii/encyclicals/documents/hf_jp-ii_enc_14091998_fides-et-ratio_sp.html

Burckhardt, Jacob (1961): Reflexiones sobre la historia universal. FCE: México. (V. O, 1905).

Casanova, José (2000): Religiones públicas en el mundo moderno. Madrid: PPC.

- (2004): “Las religiones en la era de la globalización”, Iglesia Viva, 218, pp. 69-92. Disponible en: www.iglesiaviva.org/ 218/218-31-DEBATE.pdf

- (2008): “Reconsiderar la secularización: una perspectiva comparada mundial”, Relaciones internacionales, 7, pp. 1-20. Disponible en: www.relacionesinternacionales.info/revista/revista/N7/pdf/artcasanova.pdf

- (2012): “Religión, política e igualdad de género”, Iglesia viva, 251, pp. 9-40.

Cerezo, Pedro (2010): "La secularización: una cuestión disputada”, Anales de la Real Academia de Ciencias Morales y Políticas, no 87 , pp. 363-397.

36 El afán de amparar se ha multiplicado con la toma de conciencia institucional de los peligros de la red: es motivo de insistente preocupación en la agenda digital europea, en el Safer programme, en el punto VI de la Agenda digital para España y en el Plan Estatal de Ciencia y Técnica e Innovación, 6.4.7. "Reto en economía y sociedad digital" que incluye como prioridad 7 la temática "Ciberseguridad y confianza digital... ·(iii) protección a colectivos especialmente vulnerables". Responde al interés institucional de promover la protección de los menores la autorregulación suscrita en diciembre de 2011 por la Coalición CEO http://ec.europa.eu/digitalagenda/en/self-regulation-better-internet-kids. 
Feyerabend, Paul (1981): Tratado contra el método. Tecnos: Madrid. (V.0. 1975).

- (1982): La ciencia en una sociedad libre. Siglo XXI: México.

Fraijó, Manuel (1994): Filosofia de la religión. Madrid: Trota.

Gadamer, Hans G. (1977): Verdad y método. Sígueme: Madrid. (V. O. Paul Siebeck. Tubingen, 1975).

Gallego, José A. (coord.) (2007): Diez años de reflexión sobre el nacionalismo (y acerca del estado, y la nación, y la soberanía y lo hispánico). AEDOS: Tirant lo Blanch.

Grice, H.P (1957): “Meaning”, Philosophical Review, 67.

Hill, M. (1976): Sociología de la religión. Madrid: Cristiandad. (V. O. 1973)

Jonas, Hans (1995): El principio de responsabilidad: ensayo de una ética para la civilización tecnológica. Herder: Barcelona. Martín Algarra, Manuel (2003): Teoría de la comunicación: una propuesta. Tecnos: Madrid.

Niebuhr, R. (1954): The Social Sources and Denominationalism. Hamden: Conn. Shoe String Press.

Núñez ladevéze, L. (1990): La construcción del texto. Eudema: Madrid.

- (1994): Teoría y práctica de la construcción del texto. Ariel: Barcelona.

- (1996): “El catecismo de la Iglesia y el pensamiento moderno”, en Fernández, F. (ed.): Estudios sobre el catecismo. Unión Editorial: Madrid. Véase también Catecismo de la Iglesia Católica, 1102-4, pp. 35 ss., 50, 156 ss.

- (1997): "El utilitarismo y el principio de cooperación institucional”, en Manuel Fraga. Homenaje Académico. Fundación “Cánovas del Castillo”. Madrid, pp. 1111-1137.

- (2000): La ficción del pacto social. Madrid, Tecnos.

- (2005): Identidades humanas. Conflictos morales en la posmodernidad. CEC. Madrid.

- (2012): “Sobre la ambivalencia del medio de comunicación”, en McCombs, M. \& Martín Algarra, M. (eds.): Communication and social life. Studies in honor of Professor Esteban Lopez-Escobar. Eunsa: Pamplona.

Pérez Agote, Alfonso (2012): Cambio religioso en España: los avatares de la secularización. Madrid: CIS.

Torrecillas, Teresa: (2011): Los niños frente a la televisión. Prácticas y mediación familiar. Madrid: Editorial Universitas.

Ortega y Gasset, J. (2006). “Meditación de la técnica”, en Obras completas, t. V., pp. 551-605. Madrid: Ediciones Santillana \& Fundación Ortega y Gasset.

Panikkar, Raimundo (1994): Pensamiento científico y pensamiento cristiano. Maliaño: Sal Terrae.

- (1994): “La religión del futuro”, en Fraijó, M. (1994): Filosofia de la religión. Madrid: Trota. 
- (2003): El diálogo indispensable: paz entre las religiones. Barcelona: Península.

Ratzinger, J. (2011): “La nueva evangelización”, L’Osservatore romano. (ed. en lengua española), 19 de enero 2001. Disponible en: http://www.zenit.org/es/articles/la-nueva-evangelizacion-segun-joseph-ratzinger http://www.vatican.va/ roman_curia/synod/documents/rc_synod_doc_20121026_message-synod_sp.html

Searle, J. R. (1997): La construcción de la realidad social. Paidós: Buenos Aires. (V. o. Nueva York. Simon\&Schuster, 1995).

Troeltsch, Ernst. (1951): El protestantismo y el mundo moderno. México: FCE. (V.o. 1925).

Tschannen, Olivier (1992): Les théories de la sécularisation. Genêve: Droz.

Werblowsky, R. J. (1981): Más allá de la tradición y la modernidad. FCE: México. (V.o. 1976)

Wittgenstein, Ludwig. (1988): Investigaciones filosóficas. México: UNAM. 